\title{
Vertical cities - the new form of high-rise construction evolution
}

\author{
Vera A. Akristiniy ${ }^{1,{ }^{*}}$ and Yulia I. Boriskina ${ }^{1}$ \\ ${ }^{1}$ Moscow State University of Civil Engineering, Yaroslavskoe shosse, 26, Moscow, 129337, Russia
}

\begin{abstract}
The article considers the basic principles of the vertical cities formation for the creation of a comfortable urban environment in conditions of rapid population growth and limited territories. As urban growth increases, there is a need for new concepts and approaches to urban space planning through the massive introduction of high-rise construction. The authors analyzed and systematized the list of high-tech solutions for arrangement the space of vertical cities, which are an integral part of the creation of the methodology for forming a high-rise buildings. Their concept differs in scale, presence of the big areas of public spaces, tendencies to selfsufficiency and sustainability, opportunity to offer the new unique comfortable environment to the population living in them.
\end{abstract}

\section{Introduction}

The cities are the place of residence for a half of the population of Earth, their architecture, structure, and ecology exert considerable impact on inhabitants. This article deals with the evolution of cities, the main principles of their development and the formation of a comfortable urban environment for procuring vital activities.

Multifunctional use of urban territories risks losing its social and compositional significance and directly dependent on the economic factor. When creating new spaces and cities, architects consider past experience and offer solutions in accordance with modern requirements $[1,3]$.

There are various opinions that cities emerged as warehouses and places of goods loading, defensive and offensive fortresses, administrative centers for the management of irrigation systems, temples. However, the ideas of planning and ordering life in the city appeared after the emergence of cities as a result of urban civilization, or the conditions for its foundation.

The form of the city is a spatial organization of the population vital activity processes and its interaction with surrounding space. Formation of space regularities are of interest: the functional zones, communications realized by structure, the basic rules of those communications. These are ideal schemes for placing functional elements.

There are many theories about the form of the city. At each stage of the humanity development, for a certain nation and terrain, it must have its own characteristics. But no matter by which path or the theory the city developed, for many centuries all over the world

${ }^{*}$ Corresponding author: $\underline{7824666 @ \text { mail.ru }}$ 
they share one thing: they are all characterized by low-rise buildings, with rare exceptions of religious buildings, many of which were built for decades and had non-residential functions $[2,6]$.

This continued until the 19th century when the technology development and a number of economic factors created unique prerequisites for the development of high-rise construction. At that stage of development, the following factors can be identified $[1,4]$ :

1. High cost of land. Cities managed to become centers of trade, administrative, political and cultural life, which led to high demand and the growth of land value. In such circumstances, each landowner sought to maximize the efficient use of their property. The only possible way to increase the usable area was to grow upwards.

2. New materials. New materials such as glass and steel acquired the increasingly wide application. The strength of the steel made it possible to shift a significant part of the load onto it, and the glass served as a good protection against the external environment instead of the walls while being several times lighter than the traditional facade.

3. Otis elevators [11]. It is difficult to overestimate the invention by Otis of the elevators safety mechanism that catches the cabin in the event of cable tear. It was thanks to him that elevators began to transport people, not just cargo, which solved the problem of inaccessibility of high-rise floors. From the once cheap, they quickly turned into the most prestigious, allowing their new owners to admire the magnificent panoramic views.

4. New constructive solutions. Until the 19th century, the increase in the height of buildings meant a thickening of the walls, which were supposed to withstand the weight of the structure. The creation of elevators and metal frames for the walls provided an opportunity for architects and engineers to design and build higher and higher buildings, increasing the number of floors. Bearing capacity was transferred to the frame of the building, the load - on the foundation.

One of the countries that concentrated all these factors was the United States, a young country open to various technologies. Not surprisingly, the world's first skyscraper, built with unique new solutions, appeared in 1885 in the American industrial city of Chicago, where the high cost of land stimulated high-rise construction. Gradually, this development led to the emergence of a large number of skyscrapers around the world. For many private corporations and developers, the construction of such erections has become a matter of prestige, between the buildings a struggle has begun for the right to be named the highest in the world. Fig.1 shows the ranking of the tallest buildings as of 2018 [12].

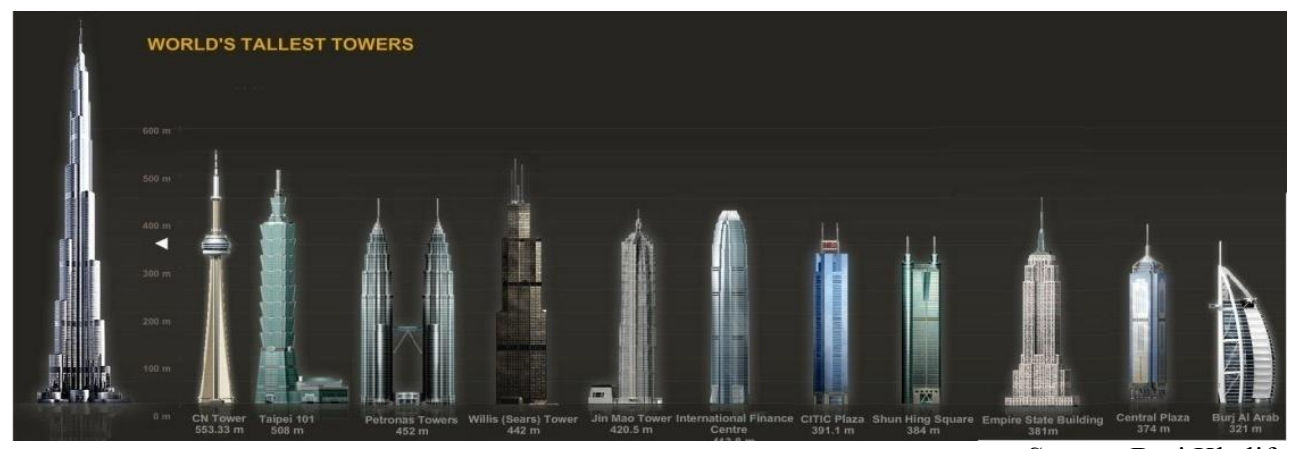

Source: Burj Khalifa

Fig.1. World's tallest Towers (from left to right: Burj Khalifa, CN Tower, Taipei 101, Petronas Towers, Willis Tower, Jin Mao Tower, International Finance Centre, Citic Plaza, Shun Hing Square, Empire State Building, Central Plaza, Burj Al Arab)

Nevertheless, despite the progress in the field of high-rise construction of individual buildings, the horizontal growth of cities increases the number of problems $[5,7]$ : 
- Urban development occupies more and more new areas, with local flora and fauna gradually disappearing. It means there is a complete destruction of the ecosystems, which have been formed for several million years.

- The city space is not used rationally, thus creating transport and social problems. Almost in any city during rush hour, it is possible to observe congestion of all transport systems.

- The presence of industrial zones in the central part of the city. This situation stems from the fact that the factories built on the outskirts of town in the last century, today are in the central part because of the high rates of urban area proliferation. In addition to environmental pollution, the negative factor is the irrational use of industrial areas, taking into account trends in urban development.

As cities grow, there is a need for new concepts and approaches to urban space planning. High-rise construction has served as a powerful incentive for the further development of construction and related technologies necessary for the development of mega-high-rise clusters, in which people can stay for a long time with no need to leave it [4,7]. In the $21 \mathrm{st}$ century, there are enough prerequisites for implementing a new concept of development in the form of vertical cities (Fig. 2).

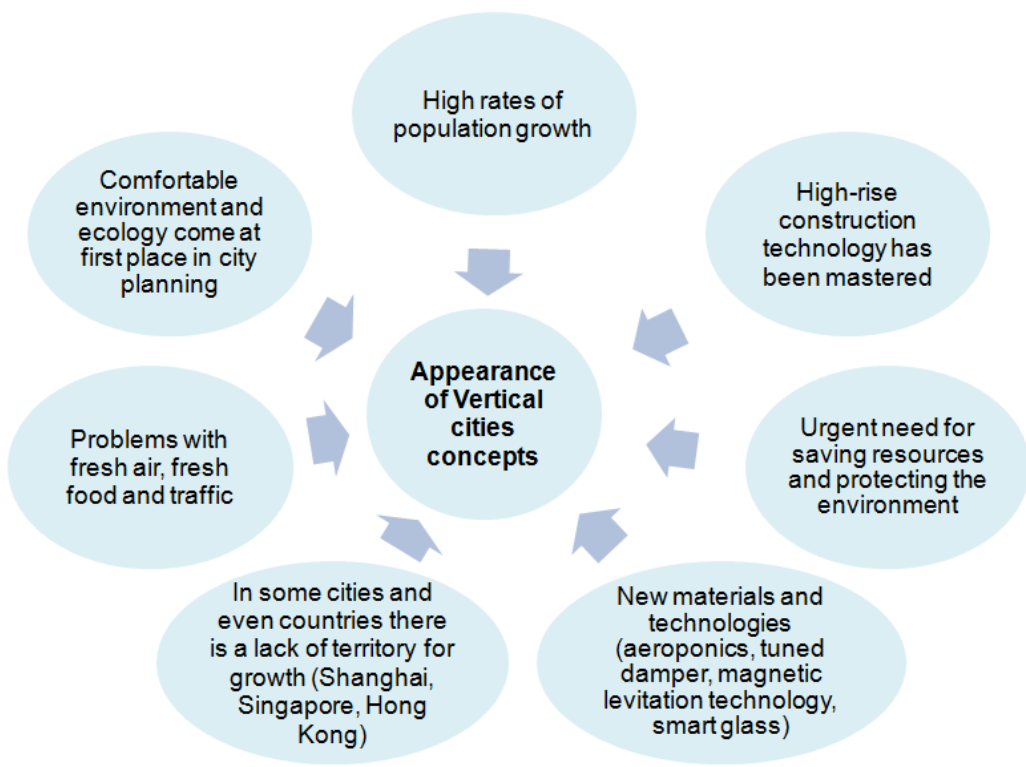

Fig.2. Prerequisites for the appearance of vertical cities

Thus, we can distinguish the following factors, which served as the basis for creating the concept of vertical cities:

1. High rates of population growth, including an increase in the proportion of the urban population, as evidenced by statistical data (Fig. 3), which must be considered in urban zoning [13]. 


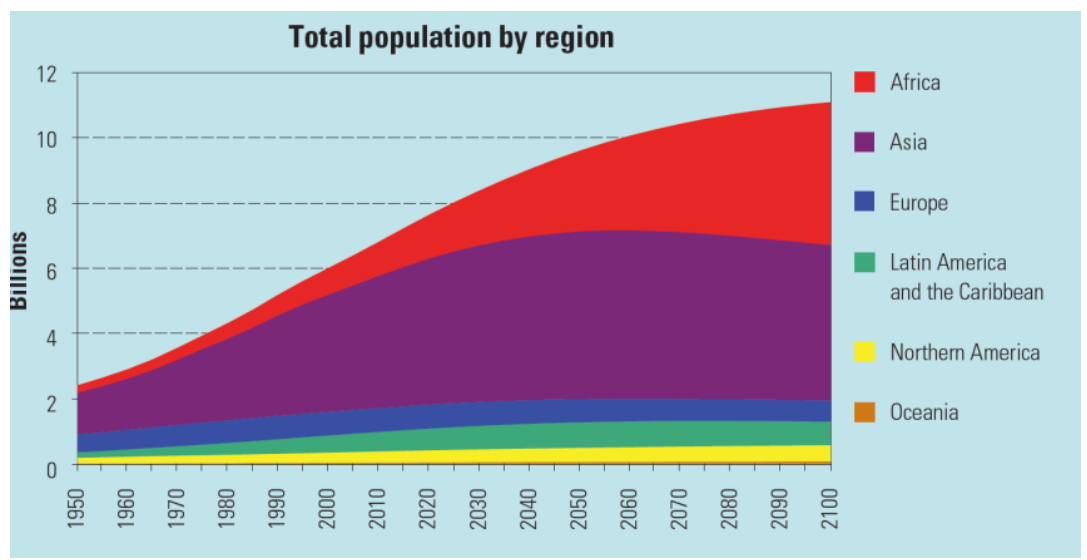

Source: Unite Nations. Department of Economic and Social Affairs

Fig. 3. World Population 2017

2. Overpopulation and deployment of a large number of industrial and transportation facilities have greatly worsened the ecological situation in the cities. A large number of harmful substances in the atmosphere, a high concentration of various types of transport, the traffic duration to the places of labor application, complicates the fresh products delivery, which grows, as a rule, outside the city. Further expansion of the city from their center will require all new communication and transport systems, the construction of which will negatively affect the ecology [8].

3. The urgent need for saving resources and protecting the environment, while the arrangement of horizontal cities does not always allow it to be done effectively, or it requires large-scale financial costs for replacing engineering communications networks or transferring objects.

4. The desire of residents to have a comfortable living, which is the main trend of the $21 \mathrm{st}$ century when designing city residential. For a favorable urban environment, people need parks, places for communication, a nice view from the windows and the opportunity to go in for sports, while moving as little as possible around the city [9].

5. Some of the largest cities lost the opportunity for growth and development due to the limited territory (Shanghai, Singapore, Hong Kong). This is connected to the obstacles of the physical terrain and to the inconvenience of their expansion for management and residence. China has announced to create a megacity, the population of which will exceed 130 million people. Megacity will be created by agglomeration of large Chinese cities: Beijing with a population of 22 million people, Hebei with a population of 14 million people and Tianjin, which has about 72 million people. The combination of such a large territory means the appearance of large distances, despite plans to provide the population with a convenient transport infrastructure $[7,10]$.

\section{Methods of creating a vertical city concept}

Currently, there is a number of technologies that can improve the level of comfort when living in vertical cities. Special technologies are developed, parts of the structures are manufactured for special orders, and the installation process itself considers the climate features, the shape of the building, the timing of construction and other specific factors. We can safely say that high-rise construction is mastered by developers to the fullest extent and they can solve any emerging problems by applying modern design and engineering solutions using existing equipment and specialists. 
The list of specialized high-tech solutions for the arrangement of vertical cities space have been systematized, serving as an integral part of creating a method of forming a high-rise cluster.

1. The newest biotechnology of aeroponics, capable of making a revolution in providing cities with food is being introduced. Aeroponics is an artificially created climate for the growth and development of plants without the use of soil and substrates [20]. With this cultivation method, the roots of the plant freely hang in the aeroponic model. The nutrient solution is supplied to the roots with micro droplets or fog, thereby creating an air-nutrient medium. The solution forms a cloud enveloping the roots, and in the pauses between spraying, aeration of the roots takes place (Fig. 4).

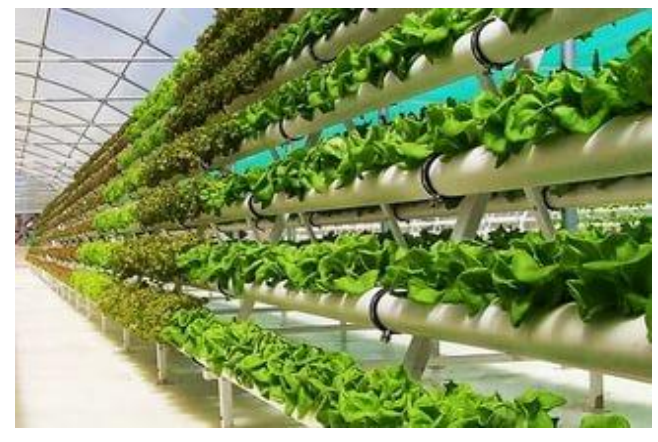

Fig. 4. Aeroponics

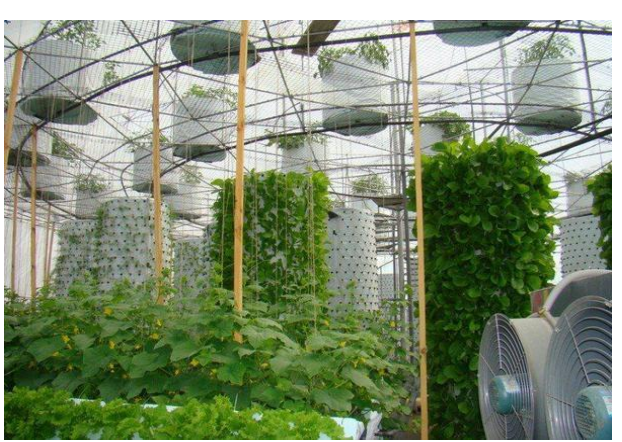

Source: greenhouses.ru

Aeroponics has many advantages [16,20], such as:

- The supply of nutrient solution and other processes controlled by the computer and correspond to the phases of plant development.

- Cultures grown on aeroponics characterized by a particularly high rate of growth and maturation.

- Active growth of roots, intensive assimilation of nutrients increases the productivity of plants, improves the quality and quantity of products.

- Accelerated period of the plant's vegetation, which allows for several harvests per year in the same area.

- Ecological compatibility, since aeroponics is a closed cycle system, there is no utilization of the nutrient solution, no use of pesticides, soil or substrates.

- The aeroponics method allows precise and quick control over all technological processes of plant growth and development.

- Low energy and material consumption of aeropon technology.

2. Technical implementation of such invention as tuned mass damper (also known as a harmonic absorber), designed to dump the high part of a building, is suggested. [14]. The safe design of high-rise buildings necessarily encounters the problem of vibrations in the upper part of the building from air currents. One of the solutions to this problem is the installation of a special high-rise tuned mass damper; an example of its effective use is the Tower of Taipei in Taiwan (Fig. 5). 


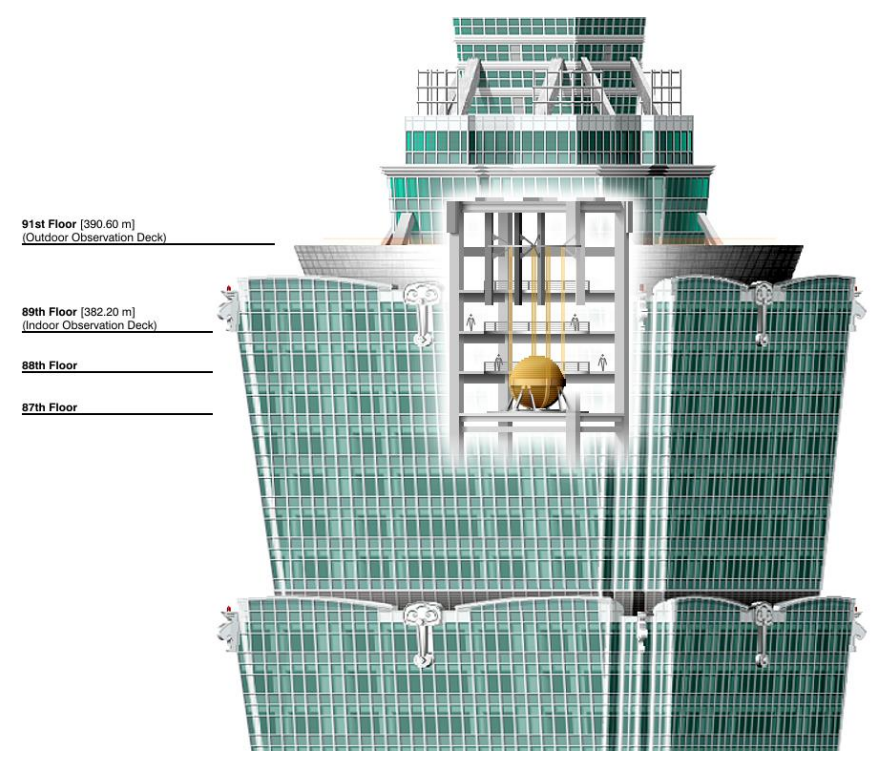

Source: en.academic.ru

Fig. 5. Scheme of the largest tuned mass damper, Tower of Taipei, Taiwan.

Firm Thornton-Tomasetti Engineers [2,23] together with the Evergreen Consulting Engineering designed 660-ton steel pendulum, which is in its operating principle an inertial vibration damper. Suspended in 87-91 floors, the pendulum oscillates, compensating for the movement of the building caused by strong gusts of wind. Its sphere, the largest in the world, consists of 41 steel plates, each $125 \mathrm{~mm}$ thick, which together is $5.4 \mathrm{~m}$ in diameter. Two other vibration dampers, each weighing 6 tons, are at the top of the spire. They soften the blows of the wind acting on the upper part of the building. The vibration energy accumulated by the dampers extinguished by a system of springs located under the dampers.

3. The practice of using smart-glass is currently widespread in the field of green building [17]. Its characteristics represent the possibility of introducing it into the glazing system of high-rise buildings. A special complex of nano-sputtering allows saving of lighting, keeping heat and preventing excessive heating from sunlight (Fig. 6,7).

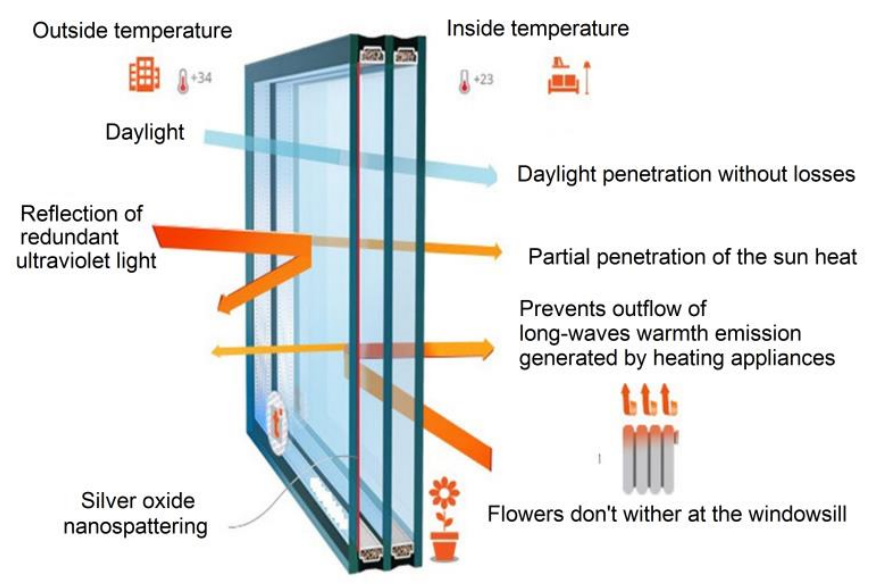

Fig. 6. Smart-glass device schematic 


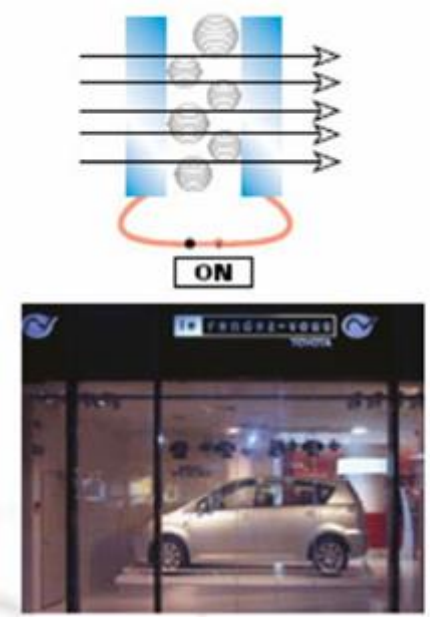

Fig. 7. The basic principle of smart-glass
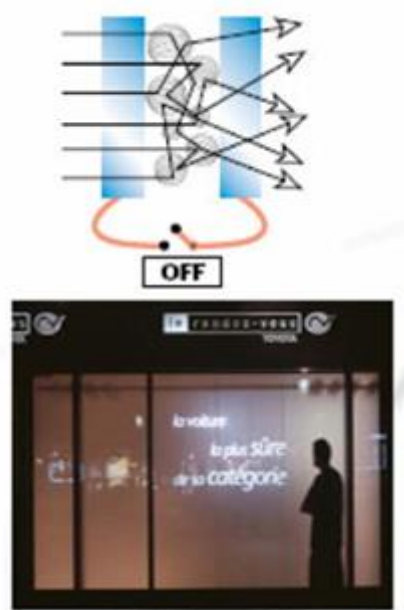

Source: kerch.biz.ua

4. The MULTI Elevators (Thyssen Group, Germany) magnetic levitation technology introduced in 2017 can be an effective and high-speed method of moving in different directions of a high-rise cluster [18]. This high-tech solution without the application of wire ropes allows the use of multiple cabins in one shaft, the direction of movement of which can be vertical, horizontal or diagonal, in the case of the enclosing structures with a certain angle of inclination to the outer or inner side (Fig. 8).

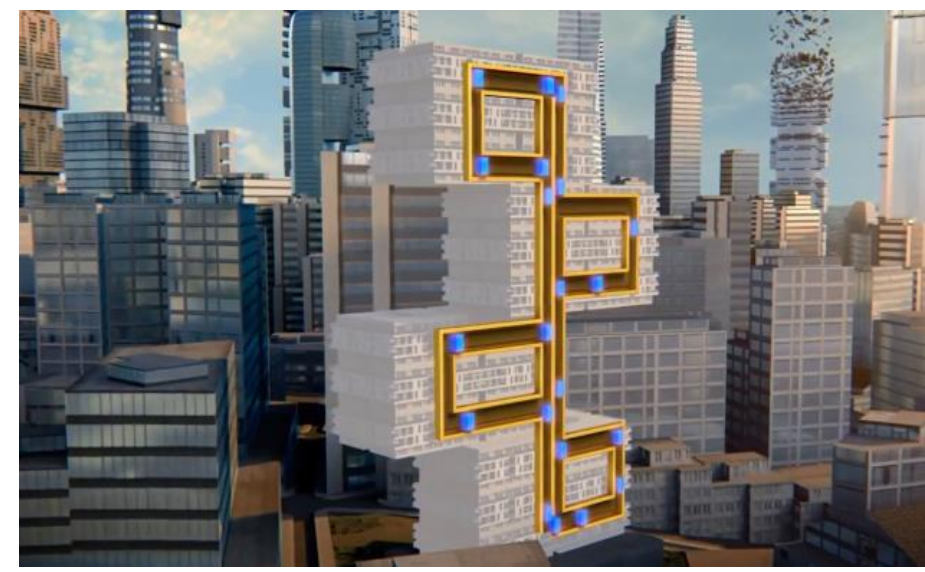

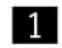
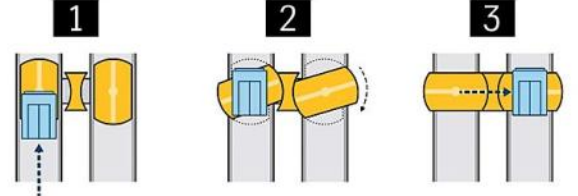

4

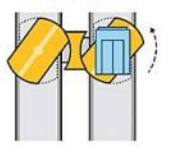

5

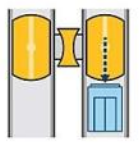

Source: multi.thyssenkrupp-elevator.com

Fig. 8. MULTI elevators (Thyssen Group, Germany) 


\section{Practical results}

Thanks to all these accumulated technologies, a possible solution to the further growth of urban space will be emergence of vertical cities, the concepts of which architects actively propose today. One of the most interesting concepts for creating a vertical city proposed by the Russian architect S. Nepomnyaschy is the heliocluster project "City of the Sun" with the possibility of introduction in any territorial zone $[6,16]$.

Helioclusters - the concept of unique multifunctional house-giants, comparable in scale and infrastructure with neighborhoods and even entire cities, which are as open to the natural light as possible. The concept is applicable to a variety of climatic conditions.

According to S. Nepomnyashchy, for 1 hectare of land in a heliocluster with a height of up to 35 floors, there will be 100,000 square meters of housing and 100,000 square meters of additional infrastructure, including offices, parks, traffic intersections, shopping areas and service facilities. One of the principled positions of the architect is the organization of the most compact and eco-friendly space, where openness to nature, contemplation of the natural landscape and safe interaction with the environment are the basis of human life. At the minimum area is arranged secluded, spacious accommodation with terraces and views of the forest or the park. Offices, parking lots, highways, stations - all of the city's elements are located inside one huge building (Fig. 9) [16].
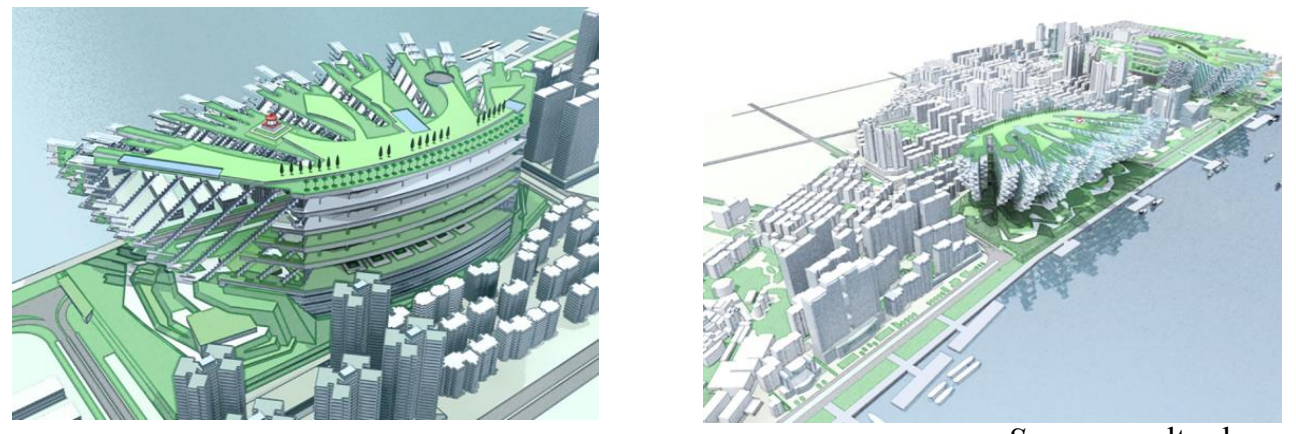

Source: realty.rbc.ru

Fig. 9. The characteristic structural elements of heliocluster

The "Heavenly Shantou gardens" heliocluster project designed for the eponymous Chinese city, introduced the developed structure of the outdoor terraces facing the sea. In the project, the main idea is to create multiple atriums with sunrooms on different levels inside the building. Light in the air will penetrate through internal channels through glass roofs or through light guides $[10,15]$. On the roof and at the base of residential buildings, the architect suggests dividing parks and gardens, building fountains and open pools (Fig. 10).
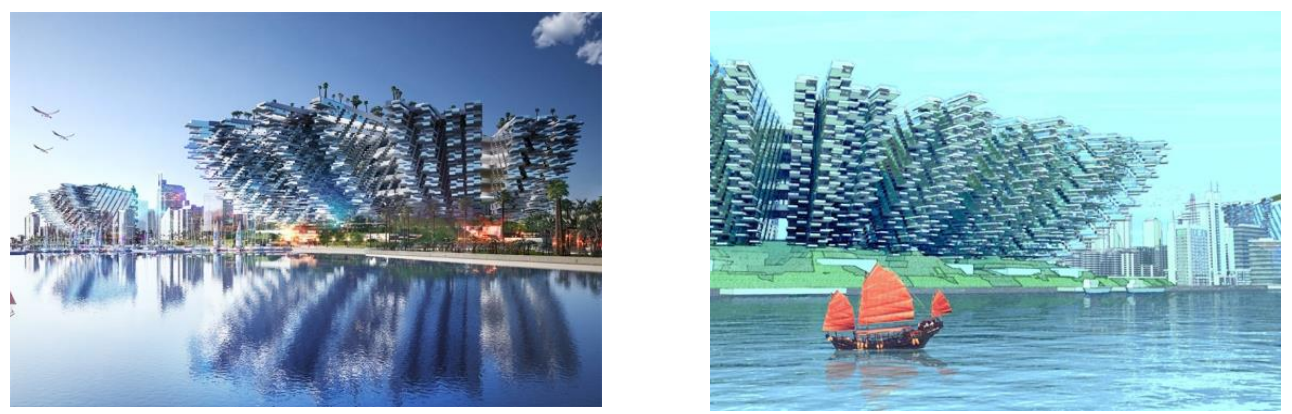

Fig. 10. The "Heavenly Shantou gardens" heliocluster project, China 
Helioclusters projects are also developed for the Moscow suburbs. In the project "Nadmoskovie", located in the northern latitudes, the architect proposes to build closed buildings, more reminiscent of mountain massifs with facade glazing and valleys on the roof. One of their main advantages is the relatively low total heat loss through the enclosing structures and the ventilation system. This is due to the fact that such structures have a much smaller ratio of the external surface to the internal volume. Even without the use of heat recovery solutions, interior lighting, people, and household appliances produce much more energy than would be lost by such a large structure [15]. The architect proposes the construction of compact blocks with an identical number of storeys, which represent separate communities with a mixed function. They will accommodate housing, retail space and office centers. Thus, the architect lays on the basis not only the convenience and comfort of living but also the economic prospects for the development of the city or district (Fig. 11).
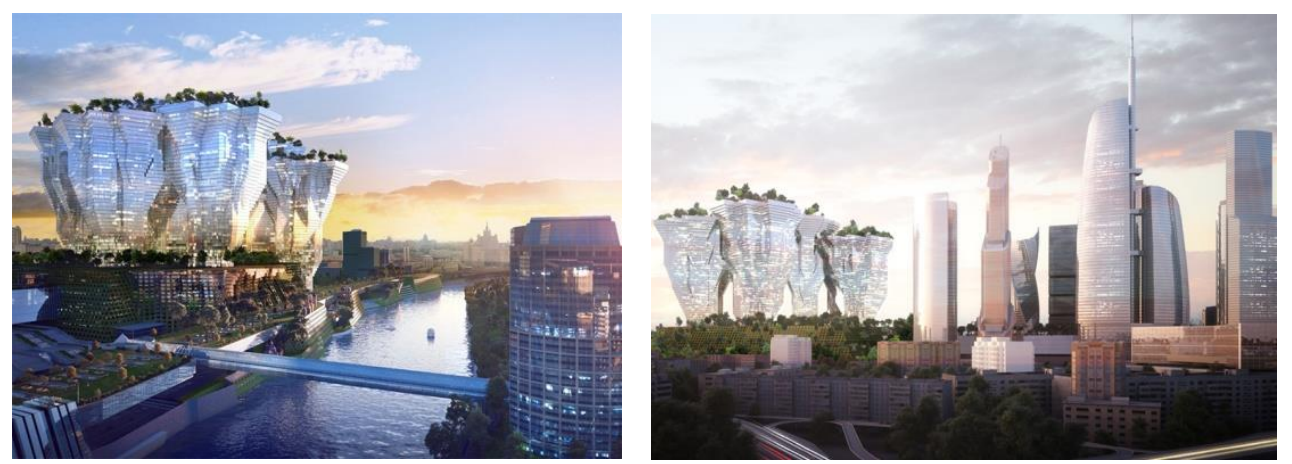

Fig. 11. "Nadmoskovie" heliocluster project, UNK Project.

The quintessence of the vertical cities concepts is the "Xtopia" project. Xtopia is an arcological project of a 300-story multifunctional building in Shanghai (China) or a vertical city. The planned height of the building should be approximately one mile (1609 meters) [16]. The main objective of the project is to solve the problems of overpopulation and to reduce the negative environmental impact caused by human populations (Fig. 12).
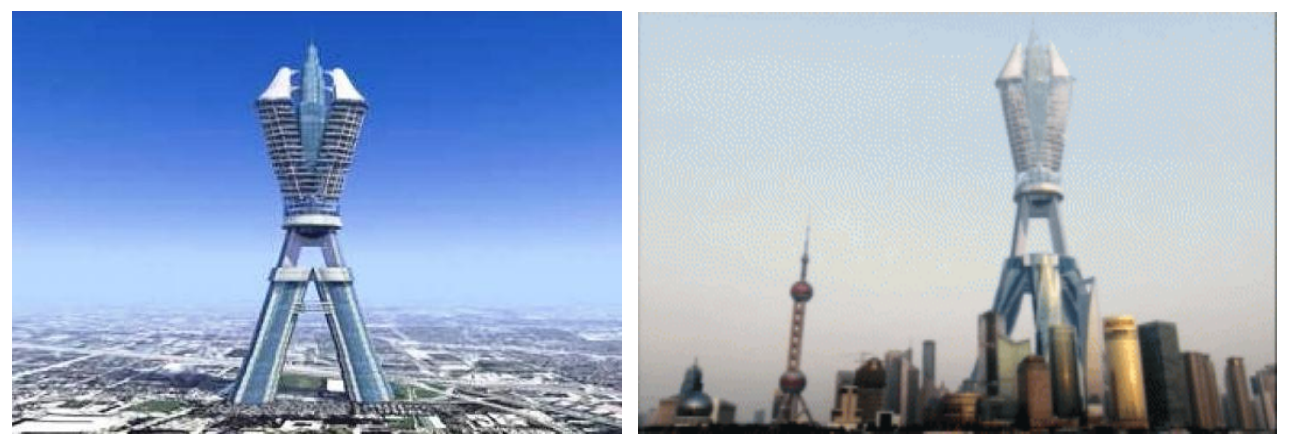

Fig. 12. The "Xtopia" heliocluster project, Shanghai, China.

Under the project, the building should accommodate about 200000 permanent residents and another 50000 people on a temporary basis in the building. For such a large number of people, the building must be functional and provide all the needs of the people inside it.

The shape of the building designed to minimize wind resistance, thereby reducing lateral 
loads. X-shaped frame located on the tripod base provides the necessary stiffness. Tuned mass damper, located in the center of the structure, will extinguish the resonant vibrations. The non-vertical shape of the building excludes the possibility of moving elevators vertically and is a typical example of the need to use elevators on a magnetic levitation system.

The building is planned to create agrarian, industrial, residential and commercial zones in order to provide all the needs of residents without a need for leaving the building. In the "tripod", there will be an industrial zone, in the center of the tower an agrarian zone, and the upper floors will occupy residential and commercial zones. The agrarian zone, according to the plan, must fully ensure the vital activity of the population living inside [19,21].

\section{Discussion}

At present, the concept of vertical cities is theoretical. However, many skyscrapers already carry a number of elements of such cities. For most major cities, such as Singapore and Shanghai, the creation of vertical cities is the next logical stage of development.

In their development, the cities went through a long and diversified path. At first, they arose and formed chaotically, at the intersection of trade routes, culture, providing the necessary minimum conditions for people's lives. The development of technology and the growth of the economic and social role of cities have led to an increase in the number of storeys and the height of buildings. Nonetheless, some high-rise buildings are no longer sufficient, their construction solves the problem of just increasing the areas of commercial and residential real estate, but not redistributing various functions of the city, zoning and providing it with the necessary resources [7,22].

A comprehensive approach requires new formats of high-rise construction. And the next stage of development is vertical cities. Their concept is different in scale, presence of a large number of public spaces, desire for self-sufficiency and environmental friendliness, opportunity to offer a new unique comfortable environment for its residents. Such concepts are especially relevant for a number of cities in South-East Asia, where population density is extremely high. The population of cities is growing at a rapid pace, over time, the concept of vertical cities will no longer seem utopian and, perhaps, in the near future the population will be able to spend almost the entire year in the structure of vertical cities, leaving them only for a trip outside the city or traveling to another country [15].

\section{Conclusion}

Regardless of form, scale and functional diversity, all cities are subject to transformation. At the same time, actual changes lag behind development needs. This leads to an imbalance and an exacerbation of the deficit of all urban spaces types, especially public spaces, open landscaped spaces, and aggravation of transport problems.

The next logical step in the development of urban planning in the right direction is the creation of a humane ecological urban environment of a new type - vertical cities [17]. Solution to ensure the required comfort characteristics of the urban environment eliminates the need for balancing on the edge between comfort and building density. High density, as an effective economic characteristic, should turn into a tool for providing comfort.

\section{References}

1. H. P. Cho, H. Lim, D. Lee, H. Cho, K. Kang, Technological Forecasting and Social Change, (2017)

2. J. Chen, J. Ma, S.M. Lo, Simulation Modelling Practice and Theory 74, 99-116 (2017) 
3. Yu-ting E, L. Zhou, Procedia Engineering 135, 2016, Pages 574-577

4. J. Fu, Q. Zheng, Y. Huang, J. Wu, Q. Liu, Engineering Structures 156, 460-471 (2018)

5. P. Lotfabadi, Renewable and Sustainable Energy Reviews 38, 285-295 (2014)

6. P. Lotfabadi, Energy and Buildings 89, 183-195 (2015)

7. J. X. Xiao, K. W. Michael Siu, Resources, Conservation and Recycling 131, 172-180 (2018)

8. P. Feng, W. Xingkuan, Procedia Engineering 21, 943-947 (2011)

9. X. Chen, H. Yang, Applied Energy 206, $541-557$ (2017)

10. L. M. Ngo, Procedia Engineering 142, $42-47$ (2016)

11. The history of Otis. Website of Otis company: http://www.otisworldwide.com / site / ru / pages / OtisHistory

12. World's Tallest Buildings 2018. http://skyscraperpage.com/diagrams/

13. World Population 2017. Unite Nations. Department of Economic and Social Affairs. Population Division. https://esa.un.org/ unpd / wpp / Publications / Files / WPP2017

14. T. Saroglou, I. A. Meir, T. Theodosiou, B. Givoni, Energy and Buildings 149, 437-449 (2017)

15. Nadmoskovie: what Russian architects see cities of the future. Website of RBC https://realty.rbc.ru/news/577d22959a7947a78ce9162a

16. Heliolatry and not only or what the future of cities. Website of Colors Life https://www.colors.life/post/112923

17. M. Al-Chalabi, Sustainable Cities and Society 18, 74-77 (2015)

18. R. Borck, Regional Science and Urban Economics 58, 13-25 (2016)

19. G. Ptichnikova, Procedia Engineering 165, 1903-1910 (2016)

20. N. Srihajong, S. Ruamrungsri, P. Terdtoon, P. Kamonpet, T. Ohyama, Applied Thermal Engineering 26(2-3), 267-276 (2006)

21. X. Wang, X. Liu, Renewable and Sustainable Energy Reviews 47, 241-259 (2015)

22. M. Al-Chalabi, Sustainable Cities and Society 18, 74-77 (2015)

23. Projects of Firm Thornton-Tomasetti Engineers http://www.thorntontomasetti.com / projects/ 